\section{LA FRONTERA ANIMAL-HUMANO}

\author{
Carmen Velayos Castelo \\ Universidad de Salamanca \\ cvelayos@usal.es
}

\section{THE ANIMAL-HUMAN BORDER}

Copyright: @ 2013 CSIC. Este es un artículo de acceso abierto distribuido bajo los términos de la licencia Creative Commons Attribution-Non Commercial (by-nc) Spain 3.0.

Recibido: 13 julio 2012. Aceptado: 6 junio 2013.

RESUMEN: Los desarrollos científicos de nuestro tiempo han enfatizado la continuidad entre los humanos y nuestros parientes antropoides. Por supuesto, los seres humanos parecen diferentes a los animales no humanos, pero tales diferencias son más bien relativas y no absolutas. Muchos autores tratan, desde hace tiempo, de rellenar la separación discursiva y artificial entre humanos y animales, separación que ha servido a su vez para justificar la relación de dominio y control sobre los segundos. Sea como fuere, la progresión de las pruebas no ha resultado siempre convincente. ¿’Por qué? Seguiremos el camino contrario. Analizaremos algunos de los argumentos más transitados a la hora de justificar la frontera ser humano-animal y trataremos de mostrar su debilidad, así como la necesidad de avanzar hacia un mundo que sustituya la frontera por criterios prácticos de responsabilidad.

PALABRAS CLAVE: Frontera humano-animal; Continuidad ontológica; Dominio.
ABSTRACT: The scientific developments of our time have emphasized the continuity between humans and our anthropoid relatives. Of course, humans appear to be different from nonhuman animals, but such differences tend to be relative rather than absolute. Many authors are seeking to bridge the discursively constructed divide that separates animals and humans to reveal a relationship of domination and control. Anyway, this accumulative evidence has not been uniformly persuasive. Why? We'll follow the opposite way. Firstly, we'll analyze some of the most popular arguments to justify the human-animal border and, secondly, we'll try to show their weakness and the necessity to move towards a world that changes borders to practical criteria of responsibility.

KEYWORDS: Human-animal border; Ontological continuity; Domination.

Es obvio que los humanos somos distintos de todos los animales, como también lo es que hasta en el más mínimo detalle de nuestra anatomía y estructura molecular constituimos una especie de grandes mamíferos. Esta contradicción es la característica más intrigante de la especie humana y, pese a ser de todos conocida, aún nos resulta difícil comprender cómo ha llegado a producirse y qué significa. (Jared Diamond, El Tercer chimpancé) 


\section{PREÁMBULO}

En su instalación Ein Haus für Schweine und Menschen (1997), las artistas performance Rosemarie Trockel y Carsten Höller, aprovechan el potencial crítico y transformador de la obra de arte para enjuiciar la relación hombre-animal.

La construcción aloja a cerdos vivos y también a los espectadores humanos de la instalación, que se convierten en parte del proceso artístico. Todos comparten un mismo hogar. Sin embargo, una pared de cristal divide a los seres humanos de los cerdos y permite que los primeros vean a los segundos, pero no al revés. Además, dentro de la casa, solo pueden verlos, no interactuar con ellos.

La casa dividida de Trockel y Höller representa la barrera artificial entre el animal no humano y el humano. Al otro lado del cristal nos sentimos seguros. Es el lugar de los derechos, del observador aparentemente distanciado de su objeto; un lugar, en suma, que justifica una relación de dominio hacia quienes quedan fuera. Solo hace falta un leve cambio de perspectiva, sin embargo, para ver al observador y al observado formando parte de un hábitat común. Es más, fuera de la casa, las barreras no existen y los humanos pueden ya tocar y acariciar a los animales.

La instalación nos recuerda que la justificación ontológica de nuestra especificidad con respecto al animal no humano, es una construcción cultural y, como tal, convencional. La naturaleza no sabe de fronteras, ésas las creamos nosotros. Aunque abierta a modificaciones históricas, la construcción ontológica y práctica dominante de la relación hombre-animal ha sido siempre la de la rígida frontera entre ellos. Esta tiene un carácter doble. Por una parte, es una escisión abierta en el orden de la naturaleza tal y como es concebido por las diversas cosmovisiones históricas. Por otra, es también una escisión práctica que legitima el dominio y la instrumentalización humana del animal, entendido como un extraño.

\section{LA FRONTERA ANIMAL-HUMANO}

Todavía en la actualidad seguimos operando con dos modelos ontológicos diferentes en lo que hace a la distinción humano-animal y a sus implicaciones normativas. El primero sigue insistiendo en la relevancia de la tesis clásica del salto cualitativo entre el animal no humano y el humano. El segundo establece, sin embargo, que entre los animales no humanos y los humanos solo existen diferencias gradativas o cuantitativas: solamente hay distintos tipos de animales, entre los que están los humanos.
La tesis de este artículo es limitada. En el contexto de los dos volúmenes de la revista Arbor destinados a revisar varias fronteras ontológicas convencionales, acogeremos el tratamiento de una de las más quebradizas - aparentemente- de nuestro momento histórico. Se insistirá en la necesidad de problematizar la tesis del salto ontológico cualitativo entre animales no humanos y animales humanos analizando algunos de los argumentos y criterios más populares para seguir justificando dicho salto y, en consecuencia, la frontera hombre-animal. No se pretende, sin embargo, tratar las consecuencias normativas de la negación de la misma, lo que nos llevaría a escribir un ensayo diferente. Pero sí propondremos una serie de cambios "primarios" de corte evaluativo-actitudinal que se desprenden necesariamente del derribe de la frontera y que afectan a la actitud general de los sujetos morales frente a otros animales.

Se insistirá en que no existe un salto cualitativo entre la naturaleza no humana y la humana que la ciencia pueda justificar. ¿Por qué se mantiene aún la tesis del salto cualitativo entre un pequeño grupo de mamíferos (los humanos) y el resto de animales? Existen varios tipos de razones:

\subsection{Razones proteccionistas}

En primer lugar, existen razones proteccionistas, en concreto, el miedo, para justificar la separación estricta de lo humano respecto a lo animal no-humano. Como señalan Ma Mar Cabezas (2013) y Stuart Youngner en la introducción a este volumen, destruir las fronteras afianzadas histórica y socialmente no es fácil. Según Mar Cabezas, por ejemplo:

las fronteras biológicas surgen de la necesidad humana de clasificar y sistematizar, afán bajo el que se encuentra un deseo de simplificar. Así, estas fronteras evitan que la complejidad de lo real haga tambalear nuestras seguridades al mismo tiempo que nos protegen ante lo desconocido, ante todo aquello que hemos decidido - por alguna razón- colocar más allá de la frontera. (Cabezas, 2013)

Seguramente, nos costaría, mucho más de lo que ya nos cuesta, transitar por un mundo simbólico-cultural en el cual no fuera posible más que la alusión a la continuidad ontológica. Seguramente eso multiplicaría los problemas a la hora de crear normas jurídicas e, incluso, obligaciones morales. Porque es evidente que las fronteras no solo demarcan espacios ontológicos diferentes sino, a la larga, obligaciones e, incluso, derechos diferentes y bien compartimentados y corre- 
lacionados con cada grupo de seres. Como argumenta Ma Mar Cabezas, resultaría angustioso carecer de fronteras para distinguir entre lo marginal y lo normal, la enfermedad y la salud o el niño y el adulto, entre otros; porque esas fronteras terminarán siendo la base sobre la que justificar otras nuevas delimitaciones, esta vez normativas, entre lo respetable y lo indiferente, entre ciertas obligaciones y su ausencia o entre lo permisible y lo sancionable.

No obstante, la utilidad o el miedo no podrán justificar este tipo de artificios convencionales. Por supuesto, las fronteras o, si se quiere, las demarcaciones, pueden ser necesarias, pero solo bajo razones suficientes que vayan más allá del temor a lo desconocido.

De no existir razones aparentes para justificar una frontera conceptual, podríamos estar incurriendo en un tipo de dicotomía debe-es. Tal dicotomía resulta falaz en cuanto omite las razones relevantes para llegar a poder concluir que los deberes mantienen una relación relevante con los hechos. La dicotomía consistiría en afirmar que algo es así (en este caso, la separación ontológico-normativa entre seres humanos y animales no humanos) porque debe serlo ya que, de lo contrario, el mundo sería ingobernable. Esta parece ser la manera de razonar de Fukuyama cuando afirma que las consecuencias de derribar la frontera serían difíciles de asumir prácticamente (Fukuyama, 2000).

\subsection{Razones identitarias}

\subsubsection{Razones identitarias en negativo}

Las razones identitarias en negativo avalan el rechazo a lo animal como lo humano fracasado, deteriorado o caricaturizado. Según los argumentos en negativo, la animalidad no es otra cosa que un mal sucedáneo de lo humano.

Horkheimer y Adorno expresaron una contundente crítica al intento filosófico de expresión de nuestra dignidad y especificidad a través de la negación de los rasgos animales:

La idea del hombre se expresa en la historia europea en su diferencia respecto al animal. Mediante la irracionalidad del animal se demuestra la dignidad del hombre. (Horkheimer, Adorno, 2001, 291).

Este tipo de abruptas demarcaciones ha servido para apoyar los valores de lo humano a través de la comparación de determinados rasgos de nuestra especie con su ausencia o con su presencia mermada. Así, por ejemplo, el humanismo hercúleo contrastó la dignitas humana con la ferocitas animal. El camino vital del hombre era el que distaba entre la irracionalidad instintiva (la ferocitas) y la racionalidad humana (la humanitas) que solo algunos individuos estaban dispuestos a ejercer.

El problema era, sin embargo, que la dicotomía era tan sesgada como injusta. De hecho, ser racional no es lo contrario a ser "un animal no humano", sino lo contrario a "ser irracional" pudiendo realizar la razón, esto es, siendo humano. El animal no humano hace lo propio a su naturaleza. Es el hombre el que - según el humanismo - se aleja de su destino cuando rehúye el estudio o la práctica de las virtudes, por ejemplo.

Tratar de demostrar la dignidad humana en negativo, esto es, anunciando lo que el ser humano no debe ser pero otras especies son, cuenta con problemas argumentativos serios. En primer lugar, porque el ser humano no puede evitar ser racional, solo abandonar su uso, mientras que otros animales no requieren los razonamientos para sobrevivir y su valor, belleza o estatus es compatible con no tener de forma estándar aquello que no necesitan. Como señalara Montaigne en su Carta a Raimundo Sanbiunde, bajo esa misma lógica, podríamos compararnos con todas esas cualidades positivas que otros animales poseen y nosotros no. Pero no lo hicimos. Optamos por ridiculizar a otros seres en cuanto copias degradadas de la humanidad, como cuando se sigue afirmando que "alguien es una bestia" o "un bruto". Pero, ya lo sabemos, si alguien es irreflexivo o imprudente no es una bestia, sino un ser humano irreflexivo o imprudente. Las bestias (antiguo sustantivo para todo animal no humano) son perfectas en lo que son y no necesitan ser degradadas a copias deficientes de ser humano.

\subsubsection{Razones identitarias en positivo}

En tercer lugar, ha sido frecuente el intento de autodefinirnos positivamente como especie, caracterizando nuestra identidad como excluyente y única.

El mérito inherente a nuestra supuesta esencia específica ha tenido consecuencias éticas y sociales evidentes desde tiempos inmemoriales. Aún hoy sigue teniéndolas cuando muchas de nuestras conductas hacia los animales podrían seguir estando apoyadas -al menos en parte- en cómo somos unos y otros. Por ejemplo, experimentamos médicamente con casi todos los animales, pero no con los humanos, a no ser en ensayos que no requieran más que males menores para nosotros, estén consentidos autónomamente, y tengan consecuencias importantes para la investigación. Por supuesto, rechazamos el caniba- 
lismo mientras se justifica aún mayoritariamente la alimentación a través de carne animal. En tercer lugar, incluso muchos de los actores y grupos concernidos con el bienestar de los animales no humanos, justificarían la posesión responsable de animales domésticos, como gatos, perros o caballos, pero rechazarían la de cualquier humano, incluso con consentimiento. ¿Podría decirse, en suma, que hay razones derivadas de propiedades exclusivas de nuestra especie que estén sirviendo para justificar las diferencias de trato entre humanos y no humanos? Eso parece, aunque de por sí las propiedades físicas u ontológicas no devengan, sin más, en razones éticas. Pero la razón, el lenguaje o la conciencia han servido históricamente como soportes o bases para argumentos éticos que pudieran consentir el "uso" de animales no humanos y el "no uso" de los humanos. No es, con todo, objeto de este breve trabajo profundizar en la evaluación de los argumentos éticos a favor de diversas conductas antropocéntricas, entre otras cosas porque estos argumentos son generalmente más complejos $-y$ diferentes - a la explicitación de diferencias ontológicas entre diversos seres. Más bien haremos lo contrario. Nos acercaremos a algunos argumentos biológicos, ontológicos o antropológicos que apoyan la exclusividad humana y exploraremos su debilidad implícita. Por último, señalaremos brevemente cómo la fronterización ontológica, sobre todo cuando esta está apoyada en determinadas propiedades que pudieran fácilmente traducirse en intereses o en la ausencia de ellos, pone más fácil la fundamentación del dominio. Por contra, la dificultad para marcar fronteras absolutas dificulta al mismo tiempo la de justificar intereses o vulnerabilidades exclusivas del ser humano.

Efectivamente, y como bien señala Dupré, hay rasgos que son únicos en algunas clases de animales. Por ejemplo, el castor es el único mamífero capaz de digerir madera y el ornitorrinco es el único mamífero venenoso (Dupré, 2007, 105). Pero, como el mismo autor sugiere, que un rasgo único esté restringido a una sola especie refleja la carencia de diversidad filogenética de su linaje, no el carácter único y especial de dicha especie:

Probablemente en algún momento solo había una única especie de murciélagos con capacidad de localización acústica, o radar. Es posible imaginar que, en el futuro distante, habrá muchas especies de mamíferos parlantes y pensantes derivados de nuestra especie. (Dupré, 2007, 105).

Además, parece que tenemos más y más evidencia sobre la existencia pasada de varias especies de homínidos, habiéndose encontrado incluso la que parece ser una nueva especie "humana" coetánea a neandertales y sapiens (Krause, 2010).

El pensamiento occidental ha hecho gala de ingentes esfuerzos por justificar cuáles sean nuestros rasgos específicos frente a los "animales", considerados estos como una categoría diferente a la humana.

Significa esto que la filosofía occidental ha postulado que un mosquito, una cigala y un gorila pertenecen a un mismo grupo de seres, a pesar de sus diferencias. En suma, significa que comparten una esencia que los separa de nosotros y que carecen de otra que solo pertenece a la especie humana. La "esencia" humana ha sido, pues, caracterizada a partir de una serie de rasgos específicos entre los que destaca la racionalidad, la autoconciencia, el lenguaje, o la cultura. Como señala Antonio Diéguez, la tesis de la esencia remite a los filósofos de la biología y a los biólogos a la hora de avalar que "hay alguna propiedad poseída desde siempre por todos y cada uno de los miembros de una especie y solo por ellos (se supone que algo así debe ser un requisito básico de cualquier supuesta esencia) (Diéguez, 2005).

El mismo autor también se hace la pregunta de un modo más laxo en el sentido de si hay alguna característica que singularice de una forma cualitativa a la especie humana frente a otras especies animales. La pregunta es ahora si existe una condición humana, una naturaleza humana, como conjunto de rasgos genotípicos y fenotípicos propios de nuestra especie.

Múltiples autores consideran que sería la cultura y su transmisión en forma de historia la que marcaría la frontera entre humanos y animales. Y, sin embargo, puede que esta diferencia esté difuminándose y perdiendo sus límites abruptos. Así lo evidencia la ingente bibliografía surgida sobre todo en la última década sobre el particular. Sabemos, por ejemplo, que las distintas comunidades de chimpancés tienen pautas diferentes y aprendidas a la hora de cazar hormigas o de hacer uso de las hojas de los árboles (para construir almohadas en el caso de los de Costa de Marfil, o como toallas en el caso de los de Gombe).

Dominantemente, sin embargo, se ha mencionado la autoconciencia como rasgo específico que no solo nos permitirá experimentar el mundo sino saber que lo hacemos.

Entre las múltiples caracterizaciones de la autoconciencia, la de Moltmann es altamente ilustrativa:

Una vaca siempre será una vaca. No pregunta ¿qué es una vaca?, ¿quién soy yo? solo el hombre pregunta así. (Moltmann, 1986, 15). 
Algunos estudios muestran, sin embargo, que algún grado de autoconciencia puede existir en algunos chimpancés, orangutanes y delfines (McLean, 2001; Diéguez, 2005, 2). Esto no significaría que fuesen capaces de reflexionar sobre ellos mismos o sobre su individualidad (reflexividad). Para algunos autores que defienden cierta autoconciencia animal no humana, los menos exigentes, bastaría con constatar que algunos animales podrían reconocerse en un espejo. Tanto chimpancés como orangutanes - parece que también los delfines- realizan conductas que - para ser explicadas - requieren reconocimiento de sí mismos - por ejemplo inspeccionan partes de su cuerpo normalmente ocultas a sus ojos, como los genitales, o las muelas; se acicalan, etc. Incluso se sospecha que podrían reconocerse en una foto-. A la chimpancé Viky se le pidió que se colocara junto a un montón de fotos de chimpancés u otro de humanos y se colocó junto a los humanos (Gardenfors, 2003).Tanto elefantes como periquitos gray africanos usan los espejos como ayuda para encontrar objetos (Wise, 2000, 269).

De un modo más exigente, se puede tratar de atribuir cierto grado de autoconciencia en un animal a través de otros indicios más estrictos que el autorreconocimiento corporal. Así, autores como Antoni Gomila solicitarían que se probase que otros animales poseyeran una teoría de la mente (Gomila, 1997, 2000), es decir, que pudieran comprender los estados mentales de los demás desde un plano intencional, y por tanto, pudieran formarse estados de segundo orden $^{1}$.

Algunos autores piensan que un síntoma de la existencia de una teoría de la mente en un animal consiste en la atención visual conjunta o la interpretación intencional de engaño. La atención visual conjunta consiste alternativamente en cruzar miradas con otros y dirigir las miradas a un objeto. Hay casos que sugieren la intención de engañar, como cuando la chimpancé Viki criada por los Hayes (1951) evitó el castigo del experimentador deteniéndose de repente y fijando su mirada en algo situado a la espalda de este como si observara una persona aproximándose. Hayes se giró cuando en realidad no había nadie y Viki pudo así escapar (Gomila, 1997, 199).

Más allá de la conciencia en este sentido, podría hablarse de la conciencia moral como capacidad de discriminar entre el bien y el mal. Jorge Riechmann, entre otros, encuentra en este rasgo (la capacidad ética), junto con nuestra capacidad tecnocientífica (que nos permitiría destruir mundos), nuestra diferencia específica (Riechmann, 2000, 135-42). Dicha diferencia no obsta para que el propio Riechmann reconozca la continuidad ontológica entre todos los animales. De hecho, no todos los humanos pueden discriminar entre el bien y el mal, ya por su edad, por accidente o por enfermedad. La constatación de la diferencia no parece, además, estar reñida con la evolución natural de las mismas, o con una explicación evolutiva de la moralidad o de la capacidad técnica. En este sentido, la interpretación antes vista de A. Gomila lleva implícita la atribución de cierto tipo de pre-subjetividad moral o de personidad a los grandes primates.

Cabe preguntarse, a este respecto, si todas las conductas altruistas presentes en otras especies animales (en cuanto disminuyen la eficacia biológica del organismo en beneficio de la de otro u otros) tienen explicación biológica (por ejemplo en relación con la supervivencia de la especie). No está muy claro. De hecho, ciertas investigaciones primatológicas, como las de Frans de Waal, o la propia Jane Goodall, entre otros (Waal, 1997, 2008; Goodall, 1986) parecen apoyar la evolución de una tendencia a la simpatía. Hay animales que, aparentemente, mueren de pena después de perder a un ser querido. También existen conductas que no pueden explicarse fácilmente si no es apelando a cierta forma de percepción - no mediada por razones evolutivas - de las necesidades del otro y a la respuesta que estas suscitan. Así, algunos primates ayudan desinteresadamente a algún otro paralítico o lisiado. Junto a estas conductas hay otras terribles por su violencia o ausencia de preocupación por el otro.

La comprensión de los demás a través de una especie de espejeo neuronal (neuronas espejo) que permite a los primates esa especie de imitación que capta las emociones de otros, deviene un dato fundamental para explicar el origen de la simpatía (Rizzolatti, 2006).

En último término, ¿por qué el que ellos no sean morales - como tampoco lo son algunos humanos en situaciones especiales - les dejaría fuera del alcance de nuestra responsabilidad? ¿Abandonamos a un enfermo sin capacidad moral al destino de la naturaleza? Aunque no es el cometido de este breve ensayo analizar estrictamente la relación entre ciertas capacidades y el estatus moral (como mérito para ser reconocido como objeto de nuestra responsabilidad), sí que dejaremos constancia de que la capacidad moral no parece condición necesaria para merecer dicho estatus (Velayos, 1996, 2001, 2005, 2008).

¿Y qué decir del lenguaje? Sabemos que las abejas se comunican a través de su vuelo indicando dónde 
están las flores para libar. Parece que tienen incluso dialectos, aunque determinados genéticamente. Los pájaros disponen de distintos cantos y gritos de alarma, así como de cortejo o de demarcación del territorio. Los delfines emiten silbidos específicos para identificar objetos concretos. Y estos son solo algunos ejemplos de formas de comunicación animal.

Incluso si nada parecido al lenguaje humano, es decir, gramatical, pudiera ser encontrado espontáneamente en otras especies, cosa que está aún abierta a la discusión con los últimos hallazgos en comunicación en delfines o chimpancés, esto no significaría nuestra exclusividad. De hecho, hay humanos que piensan y no pueden hablar, cosa que la filosofía del lenguaje mayoritaria ha renunciado a explicitar. Steven $M$. Wise señala a este respecto el caso de su hija Siena quien, con seis meses de edad, podía sumar y restar los números 1, 2, 3 sin conocer una sola palabra (Wise, 2000, 159). Y es que, en su opinión, "el lenguaje no es necesario para ser consciente", premisa ampliamente defendida en el pasado. Ahora, prosigue, se sigue sosteniendo como mucho que el lenguaje está tan íntimamente ligado a la conciencia que ambos parecen inseparables. Pero incluso esta última aseveración puede incurrir en un error lógico, según Wise. Este admite que sin conciencia no hay lenguaje y que una mente que habla no es igual que una que no habla. Pero si la conciencia es necesaria para tener lenguaje, el lenguaje no lo es para tener conciencia (Wise, 2000, 158).

Hay humanos que han vivido años sin capacidad de hablar. Oliver Sacks recuerda entre otros el caso de Joseph, un niño sordo de once años y sin capacidad lingüística. Sacks constató que Joseph podía dibujar, hacer puzzles visuales y resolver problemas que requerían categorización mental. No es que no tuviera mente, sino que no la usaba en su totalidad. ${ }^{2}$

De todos modos, ningún animal no humano parece tener lenguaje en un sentido estricto, si por estricto entendemos el lenguaje gramatical humano, ni capacidad para aprenderlo. A pesar de los intentos de enseñar lenguajes humanos a chimpancés, bonobos y orangutanes, estas especies carecen de comunicación lingüística en su medio natural, no la desarrollan espontáneamente en un contexto de interacción con humanos, sino solo a través de programas de refuerzo y aprendizaje controlado, y solo en el caso de animales criados en cautividad. Mientras que respecto a la intencionalidad existen menos dudas a la hora de atribuírsela a los primates, no ocurre así con el lenguaje (Gomila, 1997, 2000):
Sus emisiones no son propiamente lingüísticas, señala Gomila, en la medida en que carecen de estructura gramatical. Finalmente se ha puesto en duda que los medios de comunicación desarrollados utilicen propiamente símbolos, esto es, signos convencionales que constituyan un código, en base a que los intercambios comunicativos se restringen únicamente a sus cuidadores, y no a cualquiera que intente comunicarse. (Gomila, 2000, 383).

En todo caso, el estudio sobre el lenguaje en otros animales, primates o no primates (como los delfines, por ejemplo), seguirá ofreciéndonos claves importantes para reinterpretar el conocimiento sobre nuestros hermanos evolutivos y las capacidades comunicativas específicas de las distintas especies. Pero también para acercar a ciertos animales a nuestra frágil condición, ya que el lenguaje, de nuevo, es producto de una larga evolución. Un chimpancé reconoce signos y combina parejas de ellos. El bonobo Kanzi, criado a la vez que un niño, era capaz incluso de obedecer órdenes para las que no había sido entrenado. Su nivel de éxito es similar al de un niño de dos años recibiendo órdenes, es decir, de un 70\% (Savage-Rumbaugh et al., 1993; Blasco, 2011, 42).

Sin embargo, la sintaxis, una propiedad emergente, no es una propiedad del lenguaje animal no-humano de acuerdo con el conocimiento actual del mismo. Blasco resume por qué es importante la sintaxis: "la sintaxis permite hacer autorreferencias; una frase puede componerse de sujeto-verbo-predicado pero a su vez el sujeto y el predicado pueden expandirse en una frase completa cada uno; por ejemplo, $<<$ El chico besó a la chica >> puede pasar a ser $<<$ El chico que viste al venir de Valencia besó a la chica que le gustaba>>. La recursividad es la posibilidad del lenguaje de utilizar frases dentro de frases (Blasco, 2011, nota 4, 43).

Pero ni siquiera el lenguaje con sintaxis es un elemento demarcador del ser humano frente al animal. Hay humanos, como autistas o personas con el "trastorno pragmático del lenguaje" que tienen alterada la sintaxis o no logran ni siquiera hablar.

Por último, y aunque esto no pueda ser desarrollado en esta ocasión, la ausencia de lenguaje no supone para un animal la ausencia de vulnerabilidad ante las interferencias en sus intereses. En mi opinión, un animal es vulnerable al daño en cuanto es consciente de ese daño, no porque atribuya intencionalidad a su autor, sino simplemente porque lo padezca.

\subsection{Fronteras creenciales}

Una rígida frontera ontológica entre el animal y el ser humano es característica de determinados credos 
religiosos que se han visto cuestionados continuamente por los movimientos de liberación animal.

La tradición de la Iglesia católica, por ejemplo, ha mantenido históricamente que la realidad espiritual del ser humano no se puede explicar por mera reducción a la materia. Según esto, la espiritualidad no sería un mero epifenómeno de la materia, sino el resultado de un acto creador de Dios. Esta tesis no es incompatible con la evolución, es decir, con procesos evolutivos desde la vida inorgánica a la vida orgánica y de esta hasta el ser humano. De hecho, Dios mismo habría sido el impulso y la causa de este proceso evolutivo.

La Iglesia católica acepta la evolución como teoría, no como una mera hipótesis. Lo que no acepta el catolicismo es la interpretación de la complejidad humana como reducible a la materia. De ese modo, se niega que el ser humano sea solo un organismo con diferencias cuantitativas - de grado- respecto a otras criaturas. Lo espiritual no surge de la materia viva. En suma, y como afirma la Encíclica Humani Generis de Pío XII en 1950, la evolución se acepta en el catolicismo respecto al cuerpo, no respecto al espíritu. El Papa Juan Pablo II en un mensaje a la Academia Pontificia (Juan Pablo II, 22 Octubre 1996), ratifica su apoyo a la teoría de la evolución y afirma casi en los mismos términos que Pío XII que "si el cuerpo humano tiene su origen en el material viviente que lo precedió, el alma espiritual fue inmediatamente creada por Dios".

Es aquí donde cierta forma de frontera surge en el conjunto de las criaturas de Dios. Por un lado, está el ser humano que, como imagen de Dios, es portador de una serie de dimensiones espirituales creadas por Dios. Por otro lado está el resto de las criaturas y el propio cuerpo del hombre, que desaparecerá con su muerte, no así su espíritu.

Esta frontera queda bien expresada por Juan Pablo II en el punto 6 de su mensaje a la Academia pontificia de ciencias. Allí se refiere a "una diferencia de orden ontológico", a "un salto ontológico". Esta "discontinuidad ontológica" no reniega de la continuidad física entre los animales y los seres humanos. Ocurre, sin embargo, que el momento del paso a lo espiritual no es objeto de ninguna observación, advierte el Pontífice:

La experiencia del saber metafísico, la de la conciencia de sí y de su índole reflexiva, la de la conciencia moral, la de la libertad o, incluso la experiencia estética y religiosa, competen al análisis de la reflexión filosóficas, mientras que la teología deduce el sentido último según los designios del Creador. (Juan Pablo II, 1996).
Juan Pablo II admitió que "los animales poseen un soplo vital recibido por Dios". Otra cosa es reconocerles un alma espiritual. Eso sí, dentro de la Iglesia católica hay quienes, como Mario Canciani, el párroco de San Giovanni, no solo ha insistido en la idea del alma de los animales sino en que, como los humanos, también ellos van al cielo (Canciani, 1990).

No obstante, esta frontera entre el ser humano y el resto de las criaturas no tiene por qué ser entendida de manera que suponga un trato utilitario de los animales no humanos por parte de la humanidad porque esa diferencia es compatible con la hermandad en cuanto criaturas de Dios. Para el catolicismo, la especificidad humana ha de ponerse al servicio del cuidado, no del desprecio o del maltrato de la naturaleza.

Cuando Dios crea al hombre, le encomienda cuidar a la naturaleza, hacerse cargo de ella. Solo una interpretación precipitada de los textos bíblicos puede hacer valer la imagen del dominio como opresión y arbitrariedad. Como afirma Xavier Pikaza, como intérprete de los textos bíblicos, "el hombre es rey de los animales como delegado de Dios. No ejerce un poder arbitrario, no puede actuar a nivel de capricho o sadismo". (Pikaza, 1997, 212).

Si el catolicismo hubiera hecho valer la interpretación más ajustada de los textos, quizás no hubiera prevalecido la interpretación que hemos visto en autores cristianos posteriores. Es a esto a lo que Christopher Derrick se refiere en su libro La creación delicada (Derrick, 1972, 35). Según Derrick, a pesar de que el cristianismo (en sentido amplio) estaba preparado para la veneración de la naturaleza no humana, siguió una dirección diferente. Con esto caería en la "herejía maniquea" que habría prevalecido -según él- en el cristianismo histórico. Un mundo teñido y bendecido por la mano de Dios, como es el cristiano cuando no se rinde a la influencia maniquea y a su desprecio hacia la materia, invita para Derrick - a la piedad cósmica.

Posiblemente la tensión entre la afirmación de la dignidad de todo lo creado y una rígida lectura antropocentrista que enfatiza la frontera ontológica entre el ser humano y el animal, está presente en toda la historia del catolicismo. No podemos olvidar, con todo, que el Catecismo de la Iglesia Católica reconoce que "el dominio concedido por el Creador al hombre sobre los seres inanimados y los seres vivos no es absoluto (...) exige un respeto religioso de la integridad de la creación (CA 37-38)". 


\section{IMPLICACIONES PRÁCTICAS GENERALES DE ROM- PER LA BARRERA}

La frontera ontológica entre los humanos y los no humanos ha ido en Occidente de la mano de la formulación ética y jurídica de una frontera práctica. Seguramente por eso, una labor importante de éticos animalistas como Peter Singer, Tom Regan, Gary Francione o Ursula Wolf, haya consistido en refutar que los animales (o muchos de ellos) no sean capaces de sentir, de sufrir o de tener algún tipo de conciencia, como la implicada en poseer deseos, por ejemplo.

Pero los éticos antropocentristas no dispuestos a que las cosas cambien mucho en cuanto a nuestras prácticas (solo lo suficiente para evitar la crueldad innecesaria), solo han tenido que seguir la estrategia tradicional de fronterización u "otrización" situando la frontera en otro sitio. En lugar de la capacidad de sentir, pasan a ser relevantes la capacidad lingüística (J. Habermas), el sentido de la justicia (J. Rawls) u otras capacidades o facultades exigentes.

Tanto estos autores como otros anteriores que dibujaron fronteras, señalarían que la frontera no significa la ausencia de una ética animal. Recordemos que Kant dibujó la frontera entre personas y cosas, pero reivindicó la no-crueldad respecto a los animales no personales: o que Sto. Tomás, forzado por una visión teleológica finalista, consideró a las criaturas no racionales como ordenadas al ser humano, pero no creyó en que a estas se las pudiera hacer lo que uno quisiera.

Creo, sin embargo, que la frontera hombre-animal termina suponiendo problemas a la construcción de una ética para los animales no humanos, así como creo que -en el caso de las éticas antropocéntricas actuales-, la otrización respecto a los seres no lingüísticos o no morales, termina suponiendo también problemas para la construcción de una ética per se. Los exigentes criterios de inclusión en la comunidad moral de la mayoría de éticas del siglo XX-XXI ponen en dificultades a las mismas para explicar por qué tenemos deberes hacia los niños, lo que choca con las intuiciones morales más arraigadas de la humanidad.

Por tanto, creo que la justificación de una frontera ontológica entre el ser humano y el animal de la que se puedan extraer consecuencias éticas relevantes ( $\sin$ necesidad de incurrir en falacia naturalista), sí tiene consecuencias prácticas. Implica, como poco, una actitud, Ilamémosla de dominio, de superioridad, de "te lo doy, pero no porque tú me lo puedas exigir", que hace muy difícil la consolidación de una verdadera responsabilidad hacia los animales.
Se conoce como "otrización" a la separación del hombre respecto a la naturaleza (Plumwood, 1993). Está claro que, salvo en determinadas cosmovisiones, para las cuales el respeto deriva del reconocimiento de aquello respetable como un "otro" (Reed, 1989), la estrategia más común para dominar a un grupo de seres consiste en separarlos respecto al conjunto de los sujetos que mantienen relaciones entre ellos.

Una de las claves de la construcción de esta separación o frontera entre los humanos y la naturaleza, como si los primeros no fueran naturales, es la identificación, tal y como la define K. Burke (1969, 264). Consiste en un acto simbólico o retórico de agrupamiento. Y, según Burke, la consustancialidad juega un papel determinante en la manera cómo los individuos se identifican con el otro o los otros (Sowards, 2006, 48).

De una manera arbitraria ya superada a nivel de lo teórico, algunas "éticas" tribales justificaban los límites del respeto a partir de la pertenencia a la tribu. Por otra parte, la ética occidental en diversos momentos excluyó a las mujeres, los indígenas o los esclavos por entender erróneamente que no eran propiamente racionales. Con la Modernidad, la ética da un salto teórico importantísimo al apostar por la universalidad y al reconocer a todo ser humano como digno de respeto. Desde entonces, la ética justifica de diversos modos la exclusión del otro animal de la comunidad moral y el agrupamiento de los humanos en torno a una característica común suficientemente importante como para dibujar los límites de los derechos y del reconocimiento moral. Esta característica suele ser en la actualidad la agencia moral y, según otra versión, el ser persona. El problema es, sin embargo, que no es tan fácil que dichas características se reconozcan sin problema a toda la especie humana en todas sus situaciones (como, por otra parte, resulta intuitivo) sin que puedan reconocerse también -en algún grado- en otros seres evolutivamente cercanos, como los grandes primates.

En terminología de la ecofeminista Karen Warren (1998), se trataría de una lógica de la dominación. Toda lógica de la dominación establece una separación dualista ente categorías (varón/mujer; ser humano/naturaleza). Dicha separación cobra la forma de jerarquía, siendo la primera categoría superior a la segunda y justificando esa superioridad el dominio sobre la segunda.

De todos modos, esta lógica que ha marcado el devenir de nuestras relaciones con los animales en Occidente (así como también en el pasado la exclusión 
de las mujeres o los humanos negros de la comunidad moral), no es la única posible. Pensemos por un momento en aquellas cosmovisiones con implicaciones éticas, como la de determinados indios norteamericanos. Las diferencias entre hermanos animales (humanos y no-humanos) no marcan en absoluto las diferencias de respeto. ¿Por qué habría de ser mejor la razón que el adorado vuelo del pájaro, por ejemplo? En estas cosmovisiones, la identificación se extiende a toda la naturaleza animal e incluso no animal. solo la necesidad de sobrevivir justifica para ellos la muerte de un jabalí u otro animal. Y, entonces, se realiza un ritual en señal de perdón cada vez que se mata a un hermano animal.

Según Warren o Plumwood, lo esencial de la postura mayoritaria en Occidente es la construcción de una frontera estricta y vertical entre los seres superiores y los inferiores. La capacidad para construir racionalmente nuestras vidas sería la característica atribuida históricamente a los seres superiores (hombres o seres humanos) frente a los inferiores.

Más allá de esta postura, el animalismo desarrollado en Occidente a partir sobre todo del siglo XIX, va a insistir en nuevas características de entrada al club moral, en concreto la capacidad de sufrir (P. Singer, por ejemplo), o la de tener creencias y deseos y sentido del futuro (T. Regan, en concreto). La posibilidad de identificación ha aumentado, pero ¿ha variado necesariamente la lógica del reconocimiento? Creo que sí, sobre todo porque el animalismo ha requerido la naturalización del animal humano.

En todo caso, la lógica reinvindicada aquí no es dualista (el mundo es heterogéneo y repleto de valores diferentes) ni jerárquica (pues no hay características naturales mejores ni peores per se ni seres superiores ni inferiores). ¿De dónde proceden las diferencias de trato hacia seres diferentes, pues?

Es evidente que la ética, sobre todo a partir de la Modernidad, constituye un quehacer específico y diferente con respecto a la ontología u otro tipo de argumentos sobre el ser. $Y$ es precisamente el origen subjetivo de la ética (aunque no desgajado de los he- chos) el que convierte a los sujetos morales en los únicos soportes de la ética. Los criterios ontológicos son posteriores y no anteriores (fundantes, determinantes) a la comunidad moral. Devienen, pues, en razones, plurales, en criterios necesitados de justificación, y no en argumentos en sí mismos (Velayos, 2005, 1996, 2001, 2008).

Estas razones, por su parte, se refieren a características (capacidad de sentir, de sufrir, de tener emociones primarias, de autonomía, de relación, etc.) en cuanto llevan aparejadas la posibilidad de tener intereses, necesidades, o un vulnerabilidad/dignidad. Por otro lado, no son fácilmente atribuibles a tipos de seres de forma específica, pues evolucionan y no aparecen ex nihilo en la naturaleza. Esto complejiza la labor del reconocimiento moral de otros seres.

Así, pues, uno de los méritos de la ética ecofeminista, entre otras, es haber enfatizado que las razones del posible reconocimiento moral de otros seres (como los animales) no derivan de la superioridad ontológica de los seres reconocidos frente a otros (plantas, etc.). Surgen del reconocimiento, a través de la empatía y de la razón, de otros animales debido a su vulnerabilidad y a la posibilidad - nuestra- de sentir con ellos. Pero también emergen de la comprensión de sus necesidades, intereses o valor. En este sentido, algunas características de algunos animales, como (1) que puedan establecer diferencias entre ellos mismos - y lo que les sucede- $-y$ otros individuos distintos, o (2) que puedan sentir placer y dolor, son claves para que los agentes morales podamos empalizar y reconocer su vulnerabilidad elocuente ante nosotros. Pero no hay "rasgos absolutos", surgidos ex nihilo en el ser humano; más bien acontecen importantes parecidos de familia entre nosotros, sofisticado polvo de estrellas, en suma, y otros seres maravillosos con los que compartimos una atmósfera y un planeta verde y azulado. A partir de aquí, deberíamos empezar a hablar de una ética amplia, interespecífica y no solo humana, entre cuyas mimbres se encuentra una ontología continuista. Ese cometido, sin embargo, supera los objetivos de este trabajo. 
1 Quienes primero plantearon esta hipótesis fueron Premack, D. y Woodruff, G en 1978: "Does the chimpancee have a theory of mind?" en Behavioral and Brain Sciences, 1, 515-526.

\section{BIBLIOGRAFÍA}

Blasco, A. (2011). Ética y bienestar animal. Madrid: Akal ciencia.

Burke, K (1969). A Rethoric of Motives. Berkeley: University of California Press.

Cabezas, M. M. (2013). "Juicios morales y fronteras biológicas: más allá de la frontera razón/emoción". Arbor, 189 (762): a052. doi: http://dx.doi.org/10.3989/ arbor.2013.762n4003

Canciani, M. (1990). El Arca de Noé. Carrocio.

Cavalieri, P.; Singer, P. (1998). El Proyecto Gran Simio. La igualdad más allá de la humanidad. Madrid: Trotta.

Derrick, C. (1972). La creación delicada. Madrid: Encuentro, 1987.

Diamond, J. (2007). El tercer chimpancé. Origen y futuro del animal humano. Barcelona: Mondadori, [1992].

Diéguez, A. (2005). “¿Hay diferencias esenciales entre hombres y animales? Animales por derecho". Thémata, 35, pp. 83-90.

Fukuyama, F. (2000). La gran ruptura. Barcelona: ediciones $B$.

Gärdenfors, P. (2003). How Homo Become Sapiens. On the Evolution of Thinking. Oxford: Blackwell.

Gomila, A. (1995). "Evolución y lenguaje". En Broncano, F. (ed). La mente humana. Enciclopedia Iberoamericana de Filosofía, Trotta-CSIC.

Gomila, A. (1997). "Personas primates". En García Gómez-Heras, J. M. (ed.), Ética del medio ambiente. Madrid: Tecnos.

Gomila, A. (2000). "Las razones de las personas primates". Laguna, Revista de Filosofía, no 7, 381-385.

Goodall, J. (1986). The Chimpanzees of Gombe. Cambridge: Harvard University Press.

Hayward, T. (1998). Political Theory and ecological values.Oxford: Polity Press.
2 Sacks, O.: Seeing Voices, University of California Press, 1976, 40.

Horkheimer, M.; Adorno, T. W. (2001). Dialéctica de la llustración. Madrid: Trotta, [1969].

Juan Pablo II (1996). "Juan Pablo II a los miembros de la Academia pontificia de ciencias reunidos en asamblea plenaria". Observatore Romano, 25 Octubre de 1996.

Jamieson, D. (1990). “Rights, Justice, and Duties to Provide Assistance: A Critique of Regan's Theory of Rights". Ethics, 100 (2), pp. 349-362.

McLean, A. N. (2001). “Cognitive abilities. The result of selective pressures on food adquisition?". Applied animal behaviour science, 71, 241-58.

Midgley, M. (1973). "The concept of beastliness: philosophy, ethics and animal behavior". Philosophy, 48, pp. 3-35.

Midgley, M. (1983). Animals and Why They Matter. Harmondsworth/Athens: Penguin Books/University of Georgia Press.

Moltmann, J. (1986). El hombre. Salamanca: Sígueme.

Montaigne, M. (1998) "Apología de Raimundo Sabunde". En Ensayos (II), Madrid, Cátedra, [1592].

Patzig, G. (1984). "Ética ecológica dentro de los límites de la mera razón”. En Hechos, normas, proposiciones. Barcelona: Alfa, pp. 201-223.

Pikaza, X (1997). “Dominad la Tierra... (Gen $1,28)$ Relato bíblico de la creación y ecología”. En García Gómez-Heras, J. M. (ed.), Ética del medio ambiente. Madrid: Tecnos, 207-223.

Plumwood, V. (1993). Feminism and the Mastery of Nature. New Cork: Routledge.

Prieto, L. (2008). El hombre y el animal: nuevas fronteras de la antropología. Madrid: BAC.

Reed, P (1989). “Man Apart: An Alternative to the Self-Realization Approach". En Environmental Ethics, vol. 11.
Regan, T. (1984). The Case for Animal Rights. London/New York: Routedge, 1988.

Riechmann, J.; Mosterín, J. (1995). Animales y ciudadanos. Madrid: Talasa.

Riechmann, J. (2000). Todos los animales somos hermanos. Barcelona: Los Libros de la Catarata.

Ritvo, H. (1995). "Border trouble: shifting the line between people and other animals- In the company of animals". Social Research, otoño.

Rizzolatti, G. (2006). Las neuronas espejo. Barcelona: Paidós.

Sacks, O. (1989). Seeing voices. University of California Press.

Savage-Rumbaugh, E. S.; Murphy, J.; Seveik, R.; Brakke, K. E.; Williams, S. y Rumbaugh, D. (1993). Language Comprehension in Ape and Child. Chicago: University of Chicago Press.

Singer, P. (1979). "Not for Humans only. The Place of non humans in Environmental Issues". En Goodpaster, K. E.; Sayre, K., Ethics and Problemes on the 21st Century. Indiana: Notre-Dame Press.

Singer, P. (1979). Ética Práctica. Barcelona: Ariel, 1984, según la traducción de Marta I. Gustavino.

Singer, P. (1990). Animal Liberation. London: Thorsons (edición revisada sobre la original de 1975), 1991. Hay edición castellana en Trotta, 1997.

Singer, P.; Regan, T. (1978). Animal Rights and Human Obligations. New Jersey: Prentice-Hall Englewood Cliffs.

Sorabji, R. (1993). Animal Minds and Human Morals. The Origins of the Western Debate. London: Duckworth.

Sowards, S. K. (2006). "Identification through orangutans. Destabilizing the nature/culture dualism". Ethics\&Environment, 11 (2), pp. 45-61. 
Velayos, C. (1996). La dimensión moral del ambiente natural: ¿necesitamos una nueva ética? Granada, Comares.

Velayos, C. (2000). "El proyecto Gran Simio y el concepto de persona: una cuestión de humanidad". Revista La Laguna, vol. 7, pp. 359-367.

Velayos, C. (2001). "La Ética y el animal no humano", en García Gómez-Heras, J. M., Ética en la Frontera. Madrid: Biblioteca Nueva, pp. 45-80.

Velayos, C. (2005). "Los derechos de los animales. Un reto para la ética". En Riech- mann, J. (coord.) (2004). Ética ecológica. Propuestas para una reorientación, pp. 135-144.

Velayos, C. (2008). “Animales genéticamente modificados, primates no humanos (la visión europea)". Arbor, 184 (730), pp 293-304.

Yourcenar, M. (1981). “¿Quién sabe si el alma del animal desciende bajo la tierra?". En El Tiempo, gran escultor. Madrid: Alfaguara, pp.155-167.

Waal, F. de (1997). Bien natural. Barcelona: Herder.
Waal, F. de (2008). Primates y filósofos. La evolución de la moral del simio al hombre. Barcelona, Paidós.

Warren, M. A. (1998). Moral Status. Oxford: Clarendon Press, 1997.

Warren, K. (1998). "El poder y la promesa de un feminismo ecológico". En Agra, M. X. (ed.), Feminismo y ecología. Granada: Comares (Ecorama), 117-146.

Wise, S. M. (2000). Rattlng the Cage. Toward legal rights for animals. Perseus Books. 